\section{Tough decisions at SERC}

\section{London}

Some large projects may have to be cancelled, not just deferred, to put the UK Science and Engineering Research Council (SERC)'s troubled finances back on course, its chairman, Sir Mark Richmond, warned last week. Fresh from discussions at the Advisory Board for the Research Councils on the allocation of the 1991-92 science budget among the five research councils, Richmond said he could not see how some of the bigger components of SERC's research programme can survive.

SERC must save $£ 40$ million to avoid a shortfall in 1991-92 (see Nature 348, 377; 29 November 1990). No decisions have yet been taken, but Richmond said that the British involvement in two space missions, which would cost SERC more than $£ 13$ million in total, is now in question: Lyman-FUSE, a far-ultraviolet astronomy collaboration with the United States and Canada, is due for launch in 1997; Spectrum-X, an X-ray astronomy mission involving the Soviet Union and a number of the European Space Agency partners, is to be launched by 1994. Two ground-based astronomy projects already deferred, a gravity-wave observatory and an eight-metre optical telescope, will also be re-examined.

Apart from balancing SERC's books in 1991-92, Richmond wants to release more money for research grants and studentships: "I think that's the way in which really bright young scientists emerge." $\mathrm{He}$ became alarmed during the $1980 \mathrm{~s}$ as grants were squeezed by the increasing costs of international programmes, and more of SERC's budget became tied up in large projects. This is partly the fault of the British public expenditure system, Richmond said, where research councils are more likely to get new money for a specific new project, rather than for support grants. "The government is not prepared to give the research councils the actual responsibility for guiding the research programme of the country", he said.

But research grants and studentships will suffer alongside major projects in SERC's immediate cost-cutting. As much as $£ 15$ million of the $£ 40$ million savings must come from studentships and grants, Richmond said.

One way to release money for smaller grants is to reduce spending on SERC's Interdisciplinary Research Centres (IRCs) over the coming years. Thirteen of these large six-year grants, which set up a team to work in a specific area of research, have been awarded over the past three years. Richmond expects fewer new IRCs in the future. The IRC is a "useful concept" in areas such as materials science where research is centred around expensive items of equipment, although Richmond said that IRC status may have been given to some research groups that could best have been supported through smaller grants.

The large proportion of SERC's spending that is taken up by international commitments is another important problem. CERN, the Geneva-based particle physics centre, will cost SERC $£ 9$ million more than expected this year, partly because Switzerland has recently developed an inflation problem. However, Richmond acknowledged that it is not "practical politics" to negotiate new terms for participation in CERN, less than three

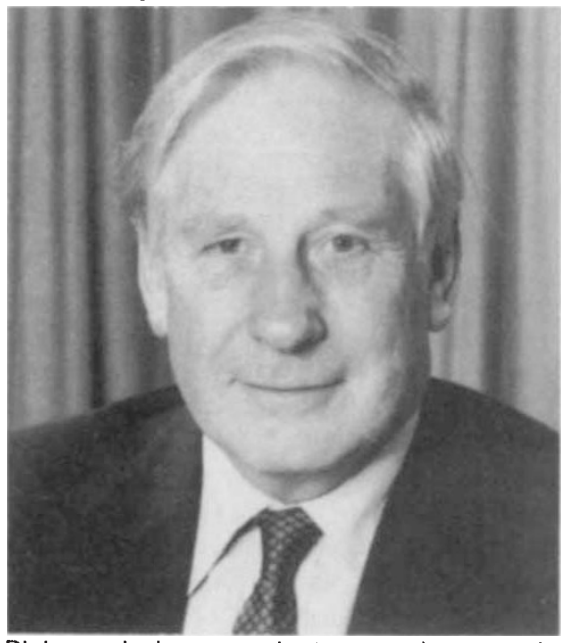

Richmond: large projects may have to be cancelled.

years after the United Kingdom instigated a major package of reforms to control costs.

Two other international agreements the European Space Agency's science programme (see opposite), and the Institute Laue-Langevin (ILL) neutron source in Grenoble - are more realistic targets for savings. ILL, a collaboration between Britain, France and Germany, currently costs SERC $£ 8.5$ million a year, and SERC must soon negotiate the UK contribution over the next five years. Britain also runs the Isis neutron source at SERC's Rutherford Appleton Laboratory, although ILL and Isis are best suited to a different range of experiments. Richmond said that SERC's Science Board must look hard at the British presence at ILL.

But Richmond is determined that the soul-searching and cutbacks at SERC should not simply leave the council supporting a smaller version of its existing programme. "We must, if we possibly can, try to generate a bit of space to start something new. At the heart of it all is flexibility - you don't know when the supernova's going to go off", he said.

Peter Aldhous

\section{ESA's science under scrutiny \\ London, Paris \& Munich}

THE European Space Agency (ESA)'s science programme, one of the Science and Engineering Research Council (SERC)'s major worries (see opposite), will be hotly debated at a two-day meeting in Paris next week. Delegates from the 13 member states hope to agree how much to spend on ESA's space science over three years from 1993 to 1995. But doubts over whether badly needed improvements to the programme's management will actually be forthcoming may delay a final decision until a high-level ministerial meeting planned for late 1991.

ESA's science budget is in trouble, plagued by cost overruns on important missions. Roger Bonnet, ESA's director of space science, has warned that some projects, such as the Huygens probe, ESA's contribution to the US Cassini mission to Saturn, may have to be cancelled.

Britain agreed the last budget increase in 1988 only after an independent review was set up to look for savings, chaired by Professor Klaus Pinkau, from the Max Planck Institute for Plasma Physics near Munich. Pinkau recommended increasing the budget to 200 million accounting units (AU) (about $£ 140$ million) in 1984 prices by 1994. But savings of $\mathbf{4 0}$ million AU a year are still needed for ESA to fund all the planned missions, and some new small projects.

The Pinkau report produced a list of cost-cutting options. The strict rule that awards equipment-manufacturing contracts to ESA member states in proportion to their financial contributions should be relaxed to get better value for money; and the science programme should be compensated for cost overruns forced by launch delays, and relieved from the excessive burden of overhead charges for use of ESA facilities. Missions should be costed more accurately and ESA bureaucracy reduced, Pinkau concluded.

Britain will be represented in Paris by the British National Space Centre, but the UK contribution is paid from SERC's budget. The new chairman, Sir Mark Richmond, said last week that until SERC is convinced that the Pinkau report will produce savings, "I can't see us commiting ourselves".

Unlike 1988, when Britain alone resisted increases, other ESA na-tions are now thought to share the British concern. Delegates are reluctant to reveal their positions in advance of the meeting, but the huge costs of reunification will in-fluence the German position. Even the French, traditionally the most enthusiastic supporters of ESA projects, are now thought to be looking for savings.

Peter Aldhous, Peter Coles \& Steven Dickman 